\title{
Combination of Left Ventricular Noncompaction and Bicuspid Aortic Valve in 19-Year-Old Male: A Case Report from Republic of Macedonia
}

\author{
Vera Spiroska*, Emilija Hristova, Sasko Kedev \\ University Clinic of Cardiology, Faculty of Medicine, Ss Cyril and Methodius University of Skopje, Skopje, Republic of \\ Macedonia
}

\begin{abstract}
Citation: Spiroska V, Hristova E, Kedev S. Combination of Left Ventricular Noncompaction and Bicuspid Aortic Valve in 19-Year-Old Male: A Case Report from Republic of Macedonia. Maced J Med Sci. $2013 \quad$ Mar 15; 6(1):65-69. http://dx.doi.org/10.3889/MJMS.1857-5773.2013.0281. Key words: Left Ventricular Noncompaction; Bicuspid Aortic Valve; echocardiography, case report; Republic of Macedonia.

"Correspondence: Vera Spiroska, MD, PhD. University Clinic of Cardiology, Faculty of Medicine, Ss Cyril and Methodius University of Skopje, Skopje, Republic of Macedonia.

E-mail: veraspiroska@yahoo.com

Received: 29-Nov-2012; Revised: 20-Jan-2013; Accepted: 28-Jan-2013; Online first: 14-Feb-2013 Copyright: ( 2013 Spiroska V. This is an openaccess article distributed under the terms of the access article distributed under the terms of the Creative Commons Attribution License, which permits unrestricted use, distribution, and reproduction in any medium, provided the original author and source are credited.

Competing Interests: The author have declared that no competing interests exist.
\end{abstract}

\begin{abstract}
Background: Noncompaction of the ventricular myocardium is a rare, unclassified cardiomyopathy due to an arrest of myocardial morphogenesis. The characteristic echocardiographic findings consist of multiple, prominent myocardial trabeculations and deep intertrabecular spaces communicating with the left ventricular cavity.
\end{abstract}

Aim: The aim of this report was to present the first case of noncompaction cardiomyopathy with bicuspid aortic valve in Republic of Macedonia.

Case Report: A 19-year-old male with the diagnosis of syncope, tachycardia with arrhythmia, and chest pain was referred to the University Clinic of Cardiology for the echocardiography. Transthoracic echocardiography showed bicuspid aortic valve with normal left ventricular (LV) dimensions and normal systolic function. Mild thickening of the aortic valve cusps and mild aortic regurgitation was found. In addition to these echocardiographic findings, prominent muscular trabeculations and deep intertrabecular spaces communicating with the ventricular cavity were observed in the infero-postero-lateral region, apical and septal portion of the LV chamber.

Conclusion: We described first case of combination of left ventricular noncompaction and bicuspid aortic valve in 19-year-old male in the Republic of Macedonia.

\section{Introduction}

Definition of non-compaction cardiomyopathy (NCC), also called spongiform cardiomyopathy, is defined as a rare congenital cardiomyopathy that affects both children and adults [1]. It results from the failure of myocardial development during embryogenesis [2][3].

During development, the majority of the heart muscle is a sponge-like meshwork of interwoven myocardial fibers. As normal development progresses, these trabeculated structures undergo significant compaction that transforms them from spongy to solid. This process is particularly apparent in the ventricles, and particularly so in the left ventricle. Noncompaction cardiomyopathy results when there is failure of this process of compaction. Because the consequence of non-compaction is particularly evident in the left ventricle, the condition is also called left ventricular noncompaction. Other hypotheses and models have been proposed, none of which is as widely accepted as the noncompaction model.

Symptoms range greatly in severity. Most are a result of a poor pumping performance by the heart. The disease can be associated with other problems with the heart and the body.

Left ventricular noncompaction (LVNC) is characterized by numerous prominent trabeculations and deep intertrabecular recesses in hypertrophied and hypokinetic segments of the left ventricle [4]. The 
mechanistic basis is thought to be an intrauterine arrest of myocardial development with lack of compaction of the loose myocardial meshwork. LVNC may occur in isolation or in association with congenital heart disease. Distinctive morphologic features can be recognized on 2-dimensional echocardiography [5]. Noncompaction of the ventricular myocardium is sometimes referred to as spongy myocardium. Stollberger et al. 2002 commented that the term 'isolated LVNC,' meaning LVNC without coexisting cardiac abnormalities, is misleading, because additional cardiac abnormalities are found in nearly all patients with LVNC [6].

A locus for autosomal dominant left ventricular noncompaction has been identified on chromosome 11p15 (LVNC2; OMIM: 609470). LVNC3 (see OMIM: 605906) is caused by mutation in the LDB3 gene on chromosome 10q22.2-q23.3. LVNC4 (see OMIM: 613424) is caused by mutation in the ACTC1 gene (OMIM: 102540) on chromosome 15q14. LVNC5 (see OMIM: 613426) is caused by mutation in the MYH7 gene (OMIM: 160760) on chromosome 14q12. LVNC6 (see OMIM: 601494) is caused by mutation in the TNNT2 gene (OMIM: 191045) on chromosome 1q32. LVNC can also occur as part of an X-linked disorder, Barth syndrome (OMIM: 302060), caused by mutation in the TAZ gene (OMIM: 300394) on chromosome Xq28.

Ichida (2009) reviewed the clinical features and genetics of left ventricular noncompaction [7]. The mode of inheritance is predominantly autosomal dominant, and sarcomere protein mutations are more common in adults. Ichida, 2009 suggested that there may be a different underlying etiology between childhood and adult cases [7]. In addition, noting the high incidence of LVNC in adults, Ichida, 2009 suggested that hypertrabeculation may occur secondary to other events and that LVNC may be overdiagnosed because of sensitive diagnostic criteria, which should be reappraised [7].

The aim of this report was to present the first case of noncompaction cardiomyopathy with bicuspid aortic valve in the Republic of Macedonia.

\section{Case Report}

A 19-year-old male with the diagnosis of syncope, tachycardia with arrhythmia, chest pain was referred to the University Clinic of Cardiology for the echocardiography. One year earlier, he began to have these symptoms. Physical examination revealed systolic murmur at the base of the heart and along the left sternal border.

Electrocardiography demonstrated sinus rhythm with tachycardia with ventricular arrhythmia. Dilated ascendant aorta was present on chest radiography.

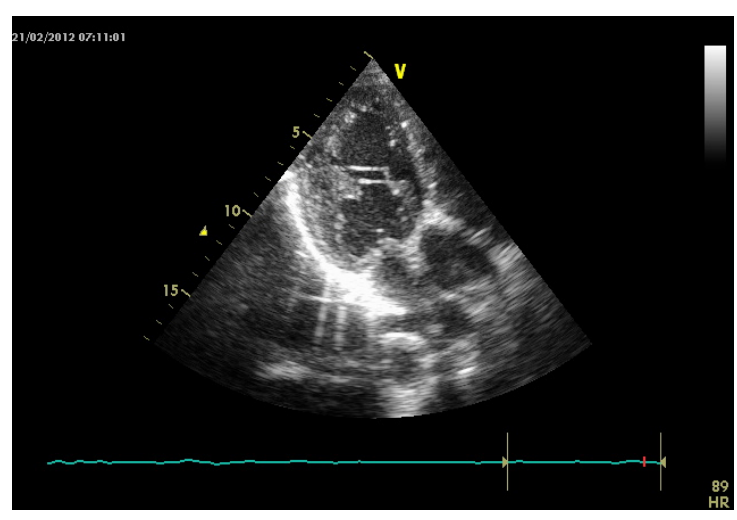

Figure 1: Apical three chamber view of left ventricle with noncompaction myocard.

Transthoracic echocardiography showed bicuspid aortic valve with normal left ventricular (LV) dimensions and normal systolic function (Figure 1). LV end-diastolic and end-systolic diameters were $42 \mathrm{~mm}$ and $24 \mathrm{~mm}$, respectively. Left ventricular ejection fraction was normal $(73 \%)$. The left and right atriums and the right ventricle were normal.

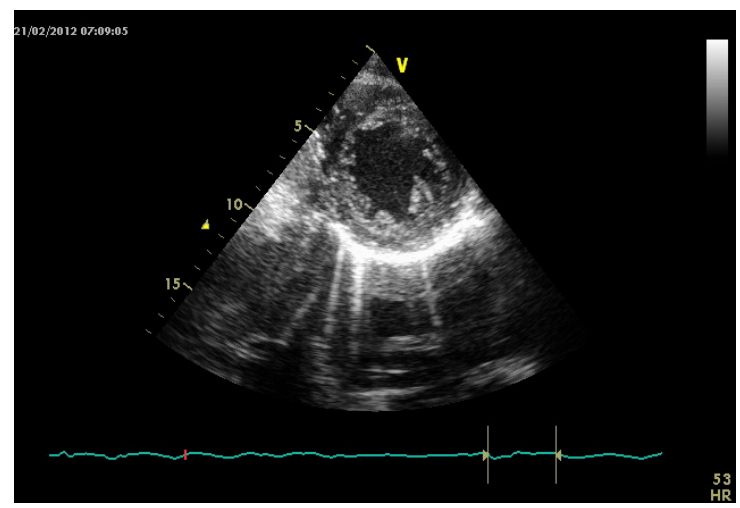

Figure 2: Short axis view of left ventricle with noncompaction myocard.

Transthoracic echocardio-graphy showed mild thickening of the aortic valve cusps and mild aortic regurgitation. However, mitral valve structure was found to be of normal appearance. In addition to these echocardiographic findings, prominent muscular trabeculations and deep intertrabecular spaces communicating with the ventricular cavity were observed in the infero-postero-lateral region, apical and septal portion of the LV chamber (Figure 2).

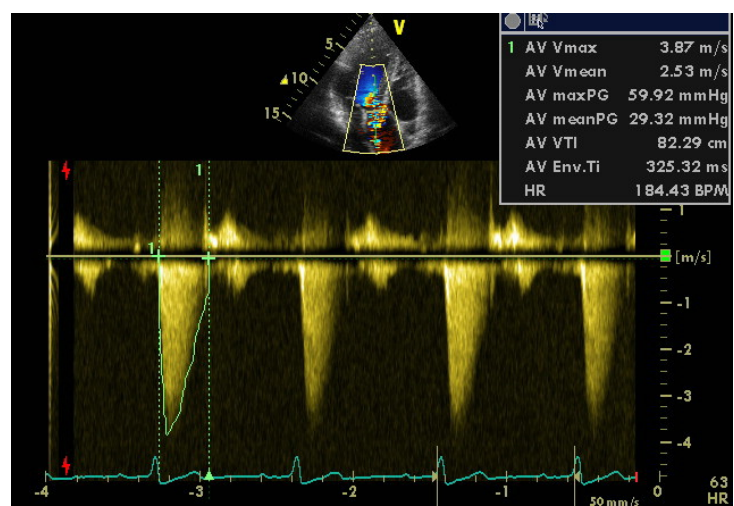

Figure 3: Doppler echocardiography of left ventricular outflow tract in patient with noncompaction left ventricle. 
Mitral regurgitation was not detected by color Doppler examination. Doppler-determined peak systolic gradient of the left ventricular outflow tract was $29.3 \mathrm{~mm} \mathrm{Hg}$ (Figures 3 and 4).

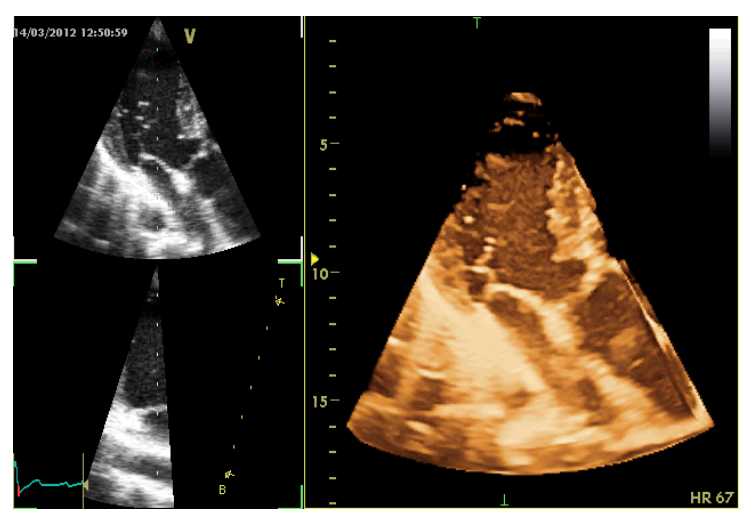

Figure 4: 3D longitudinal three chamber view in patient with noncompaction left ventricle.

\section{Discussion}

We present a 19-year-old male with the diagnosis of syncope, tachycardia with arrhythmia, and chest pain. We found by transthoracic echocardiography bicuspid aortic valve with normal left ventricular (LV) dimensions and normal systolic function. Mild thickening of the aortic valve cusps and mild aortic regurgitation was found. We also found prominent muscular trabeculations and deep intertrabecular spaces communicating with the ventricular cavity in the infero-postero-lateral region, apical and septal portion of the LV chamber.

Non compaction cardiomyopathy was first identified as an isolated condition in 1984 by Engberding and Benber [8]. They reported on a 33 year old female presenting with exertional dyspnea and palpitations. Investigations concluded persistence of myocardial sinusoids (now termed non compaction). Prior to this report, the condition was only reported in association with other cardiac anomalies, namely pulmonary or aortic atresia. Myocardial sinusoids is considered not an accurate term as endothelium lines the intertrabecular recesses.

Trabeculation of the ventricles is normal, as are prominent, discrete muscular bundles greater than $2 \mathrm{~mm}$. In non compaction there is excessively prominent trabeculations. Chin, et al. described echocardiographic method to distinguish non compaction for normal trabeculation. They described a ratio of the distance from the trough and peak, of the trabeculations, to the epicardial surface [9]. Non compaction is diagnosed when the trabeculations are more than twice the thickness of the underlying ventricular wall.

Cavusoglu et al., 2003 described two cases of noncompaction of the ventricular myocardium, in 19year-old male with bicuspid aortic valve and progressive worsening of HF, and a 61-year-old male with marked RV involvement in addition to LV apical involvement, both with the typical clinical and echocardiographic features of the disease [10]. One patient with noncompaction of the ventricular myocardium (NVM) with bicuspid aortic valve was published in 2007 which emphasizes that the concurrent congenital valvular anomalies may be more prevalent in patients with NVM than in general population. Therefore, associated congenital valve anomalies should be investigated in NVM as an associated condition contributing to ventricular dysfunction [11]. The 4th documented case of left ventricular noncompaction associated with a bicuspid aortic valve and the 1st reported case in which a patient with noncompaction underwent replacement of a bicuspid aortic valve was published [12].

A 15-year-old female patient was referred with moderate symptoms of heart failure. Echocardiography and MRI showed a bicuspid aortic valve with severe regurgitation, subaortic VSD, dilated left ventricle and left ventricular non-compaction with a moderately decreased ejection fraction, as well as isthmic coarctation and transverse arch hypoplasia [13]. Recently, two cases of NVM were reported, one associated with a ventricular septal defect and other associated with bicuspid aortic valve [14].

Unfortunately we do not have either genetic identification of noncompaction cardiomyopathy nor family analyzes in order to identify the gene mutation .

In conclusion, we described first case of combination of left ventricular noncompaction and bicuspid aortic valve in 19-year-old male in the Republic of Macedonia. To the best of our knowledge, this is 8th case in the world's literature.

\section{References}

1. Pignatelli RH, McMahon CJ, Dreyer WJ, Denfield SW, Price J, Belmont JW, Craigen WJ, Wu J, El Said H, Bezold LI, Clunie S, Fernbach S, Bowles NE, Towbin JA. Clinical characterization of left ventricular noncompaction in children: a relatively common form of cardiomyopathy. Circulation. 2003;108(21):2672-8.

2. Nilda E, Elena S, Muñóz C, Silvio J, Candace K. Noncompacted cardiomyopathy: clinical-echocardiographic study. Cardiovascular Ultrasound. 2006;4(1):35.

3. Oechslin E, Jenni R. Non-compaction of the Left Ventricular Myocardium-From Clinical Observation to the Discovery of a New Disease. European Cardiology. 2005;23:1-4.

4. Sasse-Klaassen S, Gerull B, Oechslin E, Jenni R, Thierfelder L. Isolated noncompaction of the left ventricular myocardium in the adult is an autosomal dominant disorder in the majority of patients. Am J Med Genet A. 2003;119A(2):162-7.

5. Kurosaki K, Ikeda U, Hojo Y, Fujikawa H, Katsuki T, Shimada $\mathrm{K}$. Familial isolated noncompaction of the left ventricular myocardium. Cardiology. 1999;91(1):69-72.

6. Stöllberger C, Finsterer J, Blazek G. Left ventricular hypertrabeculation/noncompaction and association with additional cardiac abnormalities and neuromuscular disorders. Am J Cardiol. 2002;90(8):899-902. 
7. Ichida F, Tsubata S, Bowles KR, Haneda N, Uese K, Miyawaki T, Dreyer WJ, Messina J, Li H, Bowles NE, Towbin JA. Novel gene mutations in patients with left ventricular noncompaction or Barth syndrome. Circulation. 2001;103(9):1256-63.

8. Engberding R, Bender F. Identification of a rare congenital anomaly of the myocardium by two-dimensional echocardiography: persistence of isolated myocardial sinusoids. Am J Cardiol. 1984;53(11):1733-4.

9. Chin TK, Perloff JK, Williams RG, Jue K, Mohrmann R. Isolated noncompaction of left ventricular myocardium. A study of eight cases. Circulation. 1990;82(2):507-13.

10. Cavusoglu Y, Ata N, Timuralp B, Gorenek B, Goktekin O, Kudaiberdieva G, et al. Noncompaction of the ventricular myocardium: report of two cases with bicuspid aortic valve demonstrating poor prognosis and with prominent right ventricular involvement. Echocardiography. 2003;20(4):37983.

11. Cavuşoğlu $\mathrm{Y}$, Aslan $\mathrm{R}$, Birdane A, Ozbabalik D, Ata $\mathrm{N}$. Noncompaction of the ventricular myocardium with bicuspid aortic valve. Anadolu Kardiyol Derg. 2007;7(1):88-90.

12. Wrigley BJ, Rosin M BP. Replacement of a Congenital Bicuspid Aortic Valve. Tex Heart Inst J. 2009;36(3):241-3.

13. Myers PO, Tissot C, Cikirikcioglu M, Kalangos A. Complex aortic coarctation, regurgitant bicuspid aortic valve with VSD and ventricular non-compaction: a challenging combination. Thorac Cardiovasc Surg. 2011;59(5):313-6.

14. Doğan A, Aksoy $H$. Coexistence of congenital heart anomalies with noncompaction of the ventricular myocardium. Two case reports. Herz. 2012;37(6):699-701. 